\title{
Saimiri sciureus
}

National Cancer Institute

\section{Source}

National Cancer Institute. Saimiri sciureus. NCI Thesaurus. Code C77114.

A small diurnal primate with nails instead of claws, the Saimiri sciureus has close-cropped

fur that is olive at the shoulders tending toward orange at the back, with a black mouth

and white around its throat, ears, and eyes. The squirrel monkey's long tail is used

primarily for balance and it has the largest brain, proportionally, of all the primates.

Squirrel monkeys are used in a wide variety of biomedical research applications. 